\title{
Discovering the Potentials and Directions of Mobile Payment Applications Development an Exploratory Study in Taiwan
}

\author{
Hsuan-Hung Liu \\ Department of Information Management \\ Chinese Culture University \\ Taipei, Taiwan \\ newday168@gmail.com
}

\author{
Dwen-Ren Tsai \\ Department of Information Management \\ Chinese Culture University \\ Taipei, Taiwan \\ drtt@mail.pccu.edu.tw
}

\begin{abstract}
Globally, rapid growth of mobile payment, many consumer brands will be integrated into the trend of mobile payment applications, thereby displaying mobile payments continues to grow and change the Electronic Commerce and Mobile commerce of consumer habits. However, current literature pays attention to key issues, applications and profiles of future mobile payment, which makes both Information System service providers and firms difficult in forming corresponding strategies on developing mobile payment applications and solutions for integration with legend systems. In this study, to achieve the goal, literature review, in-depth interviews, and Unified Modeling Language (UML) are taken as our research methods. This study tried to research Prep for Mobile payments with 9 questions of 7 expert's interview, recommended to identify key issues based upon the three stages, namely "Market demand identification", "Understanding prerequisites", and "Future plans analysis". Afterwards, use UML of use case to implement mobile payment application. Finally, to help facilitate successful development of mobile payment, future directions and practical implications are also highlighted in the end of this thesis.
\end{abstract}

Keywords- Electronic commerce, Mobile commerce, Mobile payment, Depth interviews, Unified Modeling Language (UML)

\section{INTRODUCTION}

\section{A. Backgrounds}

By 2017, mobile apps will be downloaded more than 268 billion times, generating revenue of more than $\$ 77$ billion and making apps one of the most popular computing tools for users across the globe, according to Gartner, Inc. As a result, Gartner predicts that mobile users will provide personalized data streams to more than 100 apps and services every day[1]. Mobile payment usually serves three purposes. First, it is a way of making payment when few alternatives are available. Second, it is an extension of online payment for easy access and convenience. Third, it is an additional factor of authentication for enhanced security[2].

Mobile payment service providers efficient capture the whole ecosystem, relationships, and interactions amongst stakeholders (which covers firms, banks, logistics service providers, and consumers) [3]. Generally speaking, numerous manners and applications of off-line payment (or mobile payment, more specifically) have been launched and deployed by service providers. In addition, as micro payment has been a trend for mobile / electronic commerce, offline payment outperforms any other payment approaches, in terms of parallel concerns on transaction costs, required time spending, and security. What is more, as more and more manufacturers decide to embed NFC inside the smartphones, it is estimated that more than $30 \%$ of smart-phone users will hold NFC-based smart-phone, thus making mobile payment (or the so called off-line payment) a trend (or even a standard) in the foreseeable future $[4 ; 5 ; 6]$.

Analysts say that many of the products, such as those that allow money to be sent between mobile phones, do not offer anything new, since existing services - like online banking - already provide people with what they need. By 2016, the Asia-Pacific region is expected to have the largest mobile payments market, based on the value of transactions, according to Gartner. In total, mobile transactions from consumers in countries like China, Thailand and Malaysia are forecast to reach $\$ 165$ billion by 2016 , slightly ahead of Africa, where transactions are expected to top $\$ 160$ billion over the same period[13].

Developing the blueprint for mobile payment applications, it is suggested to take both NFC and QR code as the kernel for analysis. Information system integrators and service providers in understanding the whole ecosystem, and in building up a much clearer guideline / blueprint for the evolutionary updates of individual applications and efficient integrations with possible systems[7].

\section{B. RESEARCH QUESTIONS}

Whether traveler or miner, it is essential for the researcher to provide a facilitating context to encourage those who are interviewed to tell complete stories about important moments in their lives. Open ended questions, which allow respondents to construct answers collaboratively with the listener in ways that they find meaningful are suggested by Mishler[11]. An introduction to field research[12].

Liu and Tsai inductive the five contexts are Bank, MNO, Merchant, Traffic and School and the corresponding reference[3]. According to UML [8; 9; 10], we can visualize the relationships between use cases and actors through Use Case Diagram. 
Table I. Mobile payment Scenario

\begin{tabular}{|c|c|c|c|c|c|c|c|c|c|}
\hline Corp. & $\begin{array}{c}\text { China } \\
\text { Union Pay }\end{array}$ & JCB & Master & Visa & Alliance & Gartner & $\begin{array}{c}\text { NFC } \\
\text { Forum }\end{array}$ & $\begin{array}{c}\text { Taipei } \\
\text { Smart } \\
\text { Card }\end{array}$ & Total \\
\hline Traffic & & V & & & V & V & V & V & 5 \\
\hline Travel & & & & & & & & V & 1 \\
\hline Bank & V & V & V & V & V & V & V & V & 8 \\
\hline Social & & & & & & & & V & 1 \\
\hline School & & & & & & V & & V & 2 \\
\hline Merchant & & V & V & V & V & V & V & V & 7 \\
\hline Telecom & V & & & V & V & V & & V & 5 \\
\hline Medical & & & & & & V & & & 1 \\
\hline Other & V & & V & & & V & V & & 4 \\
\hline
\end{tabular}

Particularly, to help mobile advertising service providers efficient capture the whole ecosystem, Unified Modeling Language (UML) is applied as the manner for modeling and visualizing the above information. To help bridge the gap mentioned above, this study puts its focus on development of scenarios and reference models of mobile payment. To achieve the goal, literature review, in-depth interviews, and Unified Modeling Language (UML) are taken as our research methods.

\section{CORRESPONDING SCENARIOS}

Recommended to identify key issues based upon the three stages, namely "Market demand identification", "Understanding prerequisites" and "Future plans analysis".

\section{A. Market demand identification}

1.1 Why use cash higher than abroad the proportion of in Taiwan (Republic of China)? Is cash payment good, or trouble?

1.2 Banking, Telecom, Handset manufactures, System manufacturers and other industry manufacturers are paying close attention the mobile payment. What is its potential?

1.3 What's the current environment mobile payment status in Taiwan ? What aspects need open up to form use ethos?

\section{B. Units Understanding prerequisites}

2.1 What do we want to accomplish, short-term and longterm? What's the opportunity?

2.2 What do we want to do about our current payment infrastructure?

2.3 How does the solution integrate with our current payment, accounting and marketing systems? Is it open? Are there SDKs or APIs? Is it pre-integrated with my POS or marketing platform?

C. Future plans analysis

3.1 Does the solution accommodate all customers and devices, or just some?

3.2 What is the vendor's roadmap to accommodate future payment paradigms?

3.3 Are mobile payments could help improve product sales?
The 7 expert's interview, recommended to identify key issues based upon the three stages, namely "Market demand identification", "Understanding prerequisites", and "Future plans analysis". Table II, Total Expert answer rate 93\%, "Market demand identification" 95\%, "Understanding prerequisites" 90\%, and "Future plans analysis" 95\%.

Table II. Industry expert answer rate

\begin{tabular}{|c|c|c|c|c|c|c|c|c|c|c|c|}
\hline Style & Industry & 1.1 & 1.2 & 1.3 & 2.1 & 2.2 & 2.3 & 3.1 & 3.2 & 3.3 & Total \\
\hline A & Banking & V & V & V & V & V & V & V & V & V & 9 \\
\hline B & Retail & V & V & V & V & V & V & V & V & V & 9 \\
\hline C & $\begin{array}{c}\text { System } \\
\text { ntegration }\end{array}$ & V & V & V & V & V & V & V & V & V & 9 \\
\hline D & $\begin{array}{c}\text { Software } \\
\text { Design }\end{array}$ & & V & V & & & V & V & & V & 6 \\
\hline E & Telecom & V & V & V & V & V & V & V & V & V & 9 \\
\hline F & $\begin{array}{c}\text { Cash flow } \\
\text { integration }\end{array}$ & V & V & V & V & V & V & V & V & V & 9 \\
\hline G & Academia & V & V & V & V & V & V & V & V & V & 9 \\
\hline
\end{tabular}

In Table III, Table IV and Table V statistical 7 experts interviews and sum the key point of mobile payment.

Table III. Market demand identification

\begin{tabular}{|c|c|c|}
\hline 1.1 & 1.2 & 1.3 \\
\hline Payment habits (4) & Security (2). & Improve the payment \\
\hline Fee(2) & 1.Banking : & environment (3) \\
\hline Personal credit (2) & Fee, Earn exchange rate, & Marketing Mobile Payment (3) \\
\hline Financial & interest rate (2) & Cross-industry adoption (2) \\
\hline management (2) & Decrease in cash management (1) & \\
\hline Secure payment (2) & $\begin{array}{l}\text { 2.Telecom : } \\
\text { Payment convenience (1) }\end{array}$ & \\
\hline & Cash flow superiority (1) & \\
\hline & QR Code application (1) & \\
\hline & $\begin{array}{l}\text { Channel and bandwidth channel } \\
\text { advantages (1) }\end{array}$ & \\
\hline & 3.Handset manufacturers : & \\
\hline & New applications (1) & \\
\hline & $\begin{array}{l}\text { Accelerate retire for mobile } \\
\text { phone (1) }\end{array}$ & \\
\hline
\end{tabular}

Table IV. Understanding prerequisites

\begin{tabular}{|l|l|l|}
\hline 2.1 & 2.2 & 2.3 \\
\hline NFC(3)* & QR Code(4) & Have the opportunity to open \\
QR Code(2) & Bar Code(3) & tharket (4) \\
Bar Code(2) & Can use the current \\
Improve the payment & infrastructure (3) \\
Equironment cost (3) & $\begin{array}{l}\text { Equipment (1)* } \\
\text { Cash flow interfacing with } \\
\text { existing services (2) }\end{array}$ & \\
\hline
\end{tabular}

Higher weights *

Table V. Future plans analysis

\begin{tabular}{|l|l|l|}
\hline 3.1 & 3.2 & 3.3 \\
\hline $\begin{array}{l}\text { Accommodate some } \\
\text { customers (7) } \\
\text { Must be standardized (2) }\end{array}$ & $\begin{array}{l}\text { NFC(3) } \\
\text { QR Code (2) }\end{array}$ & $\begin{array}{l}\text { Sales will increase (4) } \\
\text { Mobile Payment just tool(2) }\end{array}$ \\
\hline
\end{tabular}

Use case diagram for Mobile payment, "Open an account for mobile payment", "Mobile Domain", "Internet Domain" and "Contact Domain"(Fig. 1). 


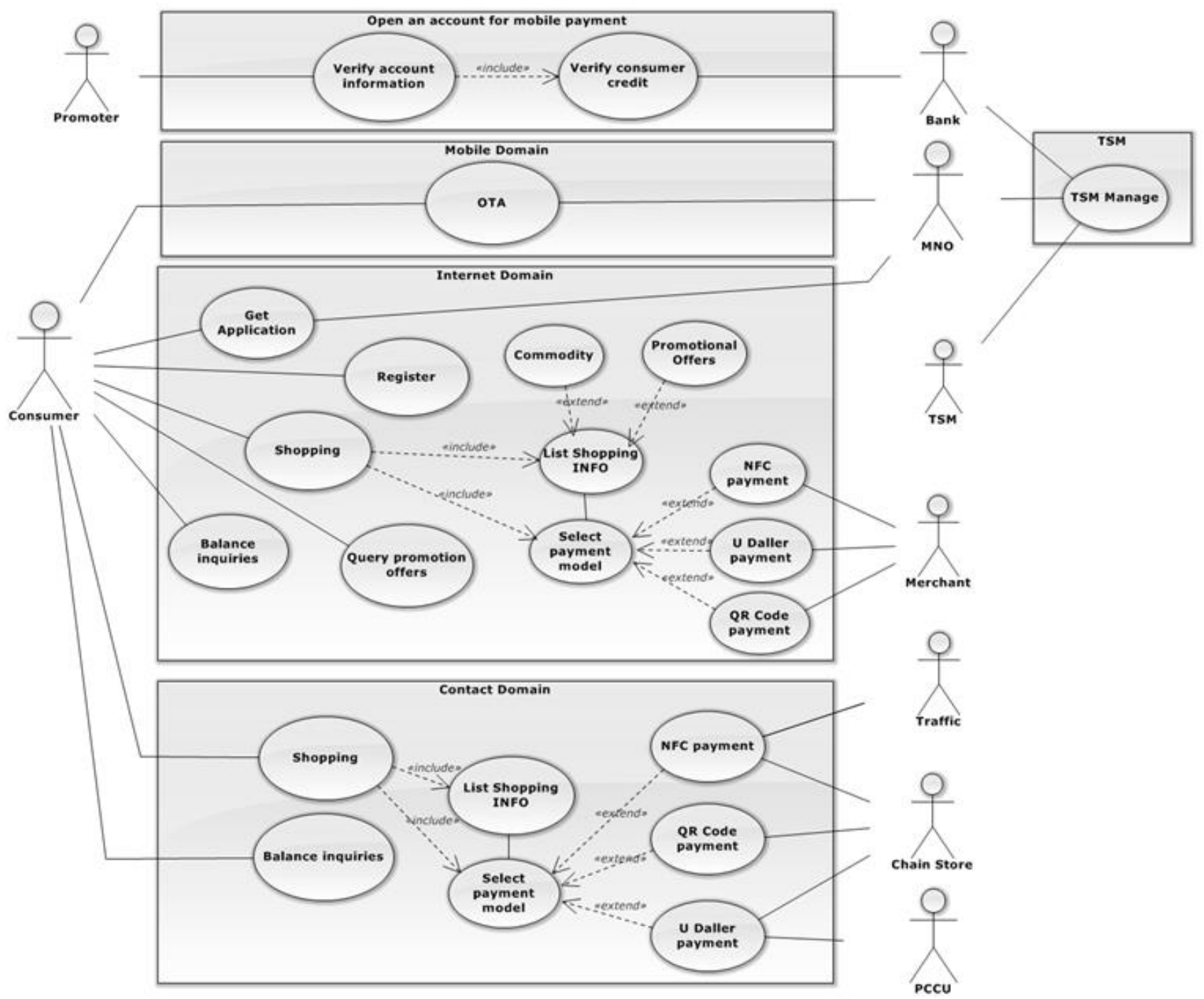

Figure1. Use case diagram for Mobile payment 


\section{CONCLUSIONS AND CONTRIBUTIONS}

Our study starts from a set of expert interviews inductive "Market demand identification", first, consumer use cash payment habits and handling charges ; second, personal credit, financial management and secure transactions, pay the highest priority to safety. The most important action to pay the payment status of marketing actions to improve the environment and action to pay ; second, cross-industry adoption.

"Understanding prerequisites", first promotion the NFC and low cost. Short term use Bar Code and QR Code, periodic task to improve the payment environment.

"Future plans analysis", Although mobile payment total solution can satisify. Finally, to help facilitate successful development of mobile payment, future directions and practical implications are also highlighted in the end of this study.

Suggestions for future work

- Increase cross-industry interviewees, the payment system that allows consumers to use after a period of time, to accept the direction of the product can be obtained.

- Bank offering mobile payment service integration to telecom operators from trusted service managers (TSM) over the air.

- $\quad$ Payment Card Industry Data Security Standard, PCIDSS.

\section{REFERENCES}

[1] Gartner(2014), Gartner Says by 2017, Mobile Users Will Provide Personalized Data Streams to More Than 100 Apps and Services Every Day,

http://www.gartner.com/newsroom/id/2654115

[2] Gartner(2012), Gartner Identifies the Top 10 Consumer Mobile Applications for 2012, http://www.gartner.com/newsroom/id/1230413

[3] Liu, H. H., Tsai, D. R. (2014), "Applying UML on the Mobile Payment Model," SEAIT-Symposium on Enterprise Architecture and Information Technology, IT23, 2013.

[4] Gartner Predicts By 2015, One-Third of Consumer Brands Will Integrate Payment Into Their Branded Mobile Apps, 2012, http://www.gartner.com/newsroom/id/2284715

[5] NFC | ABI Research, 2012, https://www.abiresearch.com/press/nfcwill-come-out-of-the-trial-phase-in-2013-as-28

[6] NFC-Enabled Handsets to Grow Nearly Tenfold from 2012 to 2017 The Mobile \&Wireless, 2013,

http://www.isuppli.com/Mobile-and-WirelessCommunications/MarketWatch/pages/NFC-Enabled-Handsets-toGrow-Nearly-Tenfold-from-2012-to-2017.aspx

[7] Liu, H. H., Tsai, D. R. (2014).“A Study on the Mobile Payment transactions mechanism in Mobile Commerce", e-CASE \& e-Tech 2014.

[8] Booch, G., Rumbaugh, J. and Jacobsen, I. (1999). "The Unified Modeling Language User Guide" Reading, Mass.: Addison-Wesley.

[9] Booch, G., Cummings, B., "Object Oriented Analysis and Design," Addison Wesley, Menlo Park, 1994.

[10] OMG, Unified Modeling Language Specification, 2010, http://www.omg.org

[11] Mishler, E. G. (1986). Research interviewing: Context and narrative. Cambridge, MA: Harvard University Press.

[12] Burgess, R. G. (1984). In the Field: An Introduction to Field Research. London, Allen and Unwin.

[13] Mark S., 2014, The Payments Challenge for Mobile CarriersNYTimes.com

http://bits.blogs.nytimes.com/2014/02/26/the-payments-challengefor-mobile-carriers/?_php=true\&_type $=$ blogs \&_r $=0$ 